\title{
Application and Examination of the Concept of Customer Experience in the Development of "Ginza Honey" Skincare Products
}

\author{
Hiroko Kawanobe ${ }^{1}$, Shoichi Kobayashi ${ }^{1}$, Takao Someya ${ }^{1}$, Atsuo Tanaka ${ }^{2}$, Shin'ya Nagasawa ${ }^{3}$ \\ ${ }^{1}$ ALBION Co., Ltd., 1-7-10 Ginza, Chuo-ku Tokyo, Japan \\ ${ }^{2}$ GINZA Honey Bee project NPO, 3-9-11 Ginza, Chuo-ku, Tokyo 104-0061, Japan \\ ${ }^{3}$ Graduate School of Commerce, Waseda University, Tokyo, Japan
}

\section{Email address:}

h_kawanobe@albion.co.jp (H. Kawanobe)

\section{To cite this article:}

Hiroko Kawanobe, Shoichi Kobayashi, Takao Someya, Atsuo Tanaka, Shin'ya Nagasawa. Application and Examination of the Concept of Customer Experience in the Development of "Ginza Honey” Skincare Products. Science Journal of Business and Management. Special Issue: Customer Experience Management/MarketingBranding. Vol. 3, No. 2-1, 2015, pp. 63-65. doi: 10.11648/j.sjbm.s.2015030201.18

\begin{abstract}
The authors applied the concept of customer experience, advocated by Bernd H. Schmitt, to the IGNIS series, skincare products manufactured and sold by ALBION Co. Ltd., who launched a line of products that contain honey collected under the Ginza Bees Project. This paper discusses this product development case, as we were able to obtain a certain level of results.
\end{abstract}

Keywords: GINZA Bees Project, Skincare Products, Customer Experience

\section{Introduction}

Using the concept of customer experience [1, 2], proposed by Bernd $\mathrm{H}$. Schmitt, a leading expert in experiential marketing, the authors have studied numerous product cases.

Of these proposed concepts, we specifically applied the concept of customer experience, advocated by Bernd $\mathrm{H}$. Schmitt, in practice with the IGNIS series - a line of skincare products manufactured and sold by ALBION Co. Ltd. We tried to increase its added value by incorporating the affective value, which is essential for high-end cosmetics, into the products in a logical manner. As a result, the customer experience of the product was communicated to consumers and the products gained a certain level of recognition in the market. This paper presents a case study of this product's research and development.

\section{The ALBION-Ginza Honey Series}

ALBION has two lines of products: the ALBION line, sold through all distribution channels of the company, and the IGNIS line, sold only at specialty stores through limited distribution channels. While the ALBION line consists of standard ALBION products, the IGNIS line was designed to be a line of skin care products that appeal to the more spiritual side of customers by being more natural and environmentally friendly to prevent its competition with the ALBION line.

The IGNIS line can be described as a group of products that really appeal to the customer's senses and convey the joys and benefits of using the products, allowing customers to understand them instantly, rather than merely their beauty. In this sense, IGNIS can be regarded as a product line that requires aesthetic value the most, among all product groups offered by ALBION.

Launched in 2011, the IGNIS H series is a line of products that contain honey collected under the NPO Ginza Bees Project, an urban beekeeping pioneer initiative. It can be said that how we convey the effectiveness of honey is critical due to the nature of the products.

\section{Experiential Marketing of the IGNIS H Skincare Products}

Skincare products have always appealed to the senses, including feelings and emotions, deviating from traditional marketing, in which the price determines the demand and 
supply depending on function and convenience. In other words, they are typical examples of affective products $[1,2]$. Therefore, besides incorporating the kansei values essential for top-selling products (e.g., a reliable effect on the skin, an enjoyable feeling that makes customers want to keep using it every day, and an "addictive" fragrance that leads to continued usage) to the product itself, factors such as the packaging design, advertising and publicity, and environment where they are sold are important. It really is essential to keep providing value consistently, from the time customers consider purchasing to when they actually purchase the product, use it, and finally, dispose of it. Therefore, it is more appropriate to think that customers are actually paying for an experience (from encountering and learning about the product to finishing with it and making a repeat purchase) rather than paying merely for its function and convenience. Figure 1 shows the IGNIS H series products.

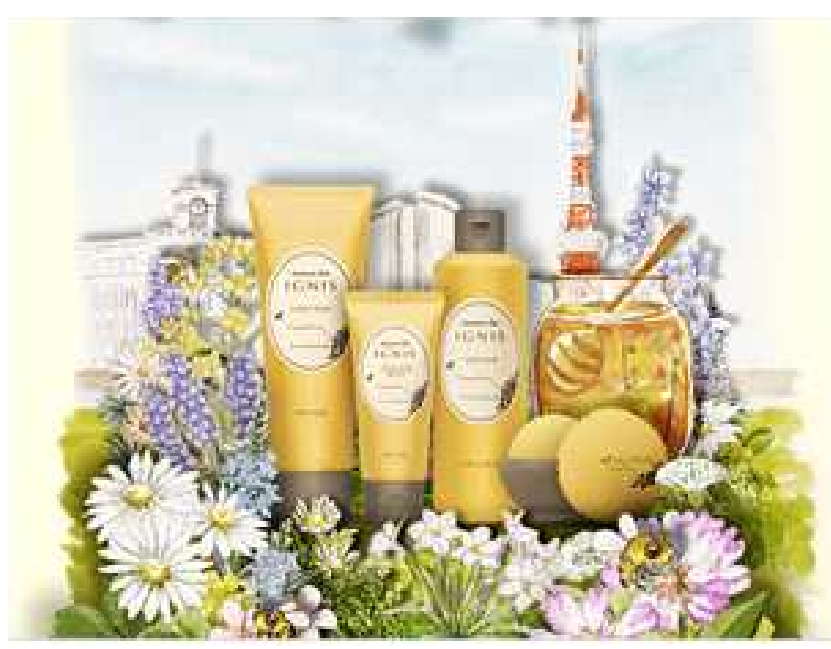

Figure 1. The IGNIS H series.

In that sense, the analysis of added value based on Bernd H. Schmitt's experiential marketing can also be considered a useful tool for product development.

In preparation for launching new products in 2011, we used the concept of experiential marketing, that consider creating new value for the new products by using the same concept to actively and thoroughly incorporate added value to the product.

Regarding honey being used as a useful component in skincare products, we believed that we should not emphasize product differentiation based on function. Instead, we felt that the greatest value addition for the products lies in the activities of the Ginza Bees Project (the producer of honey) - especially the creation of a recycling-oriented society, establishment of coexistence with nature through urban beekeeping, and in particular, the ability to participate in environmental activities even in urban areas - and the fact that environmental protection activities by a corporation led to the birth of this product line. The customer experiences of the IGNIS H series, based on Bernd H. Schmitt's strategic experiential modules (SEM), are shown in Table 1.

\section{Examination of the Shared Customer Experience}

To determine whether the customer experiences were communicated to customers, we interviewed stores with the top sales performance. The results indicated that most of the five modules of the IGNIS H series were being communicated. Using a four-point scale, including "felt it clearly," "felt it to some extent," "did not feel it much," and "did not feel it at all," the level at which the customer experience was communicated was rated. The results are shown in Table 2.

Table 1. Customer experiences of the IGNIS H series, based on Bernd H. Schmitt's SEM.

\begin{tabular}{ll}
\hline Module & Customer experience levels for the IGNIS H series \\
\hline sense & Felt it clearly \\
feel & Felt it clearly \\
think & Felt it clearly \\
act & Felt it clearly \\
relate & Did not feel it much \\
\hline
\end{tabular}

Table 2. Indicator for the level of Customer experiences communicated with consumers.

\begin{tabular}{|c|c|}
\hline Module & Customer experience of the IGNIS H series \\
\hline sense & $\begin{array}{l}\text { - Clear effect that can be felt after use } \\
\text { - Original fragrance, evocative of nature } \\
\text { - Packaging design with a honey bee motif and the Ginza } \\
\text { Bees Project logo. }\end{array}$ \\
\hline feel & $\begin{array}{l}\text { - Coexistence with nature even in the city, made possible by } \\
\text { using honey bees as a medium. }\end{array}$ \\
\hline think & $\begin{array}{l}\text { - Endorsement and support for the activities of the Ginza } \\
\text { Bees Project. }\end{array}$ \\
\hline act & $\begin{array}{l}\text { - Participation in the activities of the Ginza Bees Project. } \\
\text { - Transition to a lifestyle based on an awareness of urban } \\
\text { beekeeping and a natural recycling-based society. }\end{array}$ \\
\hline relate & $\begin{array}{l}\text { - Interactions and joint actions with others who are conscious } \\
\text { of coexistence with nature. } \\
\text { - Cooperation with communities around Ginza and various } \\
\text { environmental protection organizations. }\end{array}$ \\
\hline
\end{tabular}

\section{Results}

1) With regard to the IGNIS H series, the change in the sales of IGNIS' body care and hair care products under the same category as the IGNIS H series is shown in Figure 2. Here, we depicted the change in the quantity of sales in fiscal years 2011 and 2012, the period in which we reviewed the new products based on Bernd H. Schmitt's experiential marketing and sold them, by setting the total sales of the body care and hair care products in fiscal year 2010 at 100 and using it as the baseline to create indices.

The release of the new products increased the sales by about $30 \%$, and this sales level was steady for two years. Technically, we cannot claim that this is a contribution made solely by experiential marketing; however, we believe that this method, an example of experiential marketing application, clearly helped increase sales and demonstrated effectiveness.

2) The elements communicated by the different modules are summarized below:

With SENSE, the soft touch felt when applying the 
skincare product and the specially blended fragrance evocative of honey and nature led customers to feel mentally relaxed and make using it a habit, creating a sense of affinity.

With FEEL, the concept of "coexistence" with the natural environment in Ginza, using beekeeping as an "indicator," impressed and appealed to the customers.

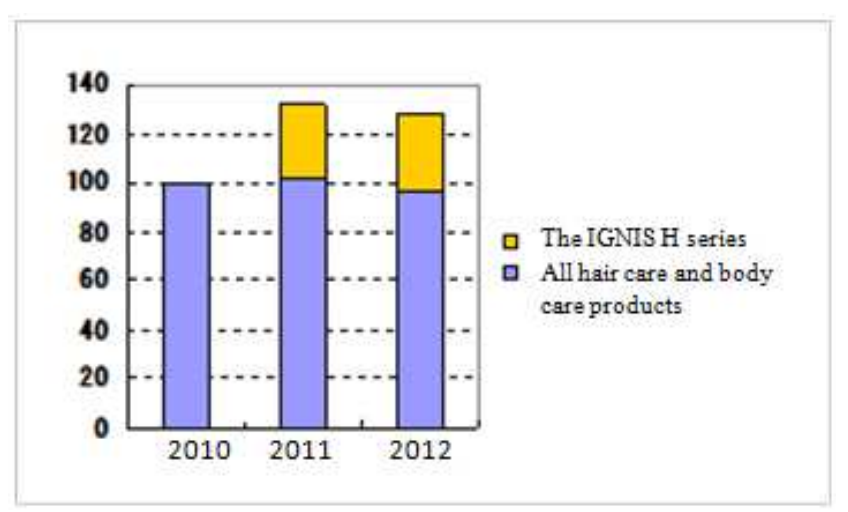

Figure 2. Sales of the Ignis H series (Total sales of 100 in 2010).

With THINK, the level of understanding was extremely high, regarding areas such as the fact that the honey bee is an environmental indicator species, honey bee habitats and beekeeping help restore the ecosystem, a large amount of honey is harvested through rooftop beekeeping in urban environments, there are very rare beeswaxes, and so on.

With ACT, each individual's interest from THINK prompted word-of-mouth communication among customers and developed a new segment of purchasers not found in the existing customer base.

In this study, the methods of conveying each module to customers included IGNIS' branding website, IGNIS' biannual magazine, various media, and social networking sites (SNS) such as Twitter and Face book, in addition to introducing the products at the store while assisting customers, which is a conventional method. These channels made it possible to communicate information to existing as well as potential customers.

However, RELATE is a customer experience that is often not communicated to customers. Although there are customers who support the value of RELATE activities and wish to participate, their involvement is limited to indirect contributions through the products, because it is not possible to provide sufficient opportunities that allow people to stay involved.

The paper showed that it is difficult to communicate customer experiences simply by disseminating information

3) Based on these results, we can conclude that the IGNIS $\mathrm{H}$ series provided the customer experiences categorized under the five modules to customers, who, in turn, endorsed and supported the product line because they were impressed by those customer experiences.

\section{Discussion}

1) It has always been difficult to incorporate affective values into luxury skincare products in a logical manner. However, by using the concept of customer experience, we increased the affective value and successfully created products that appeal to customers emotionally and win their support. We can conclude that new product was successful and led to sustained sales growth.

2) The customer experiences of FEEL and THINK were communicated to the existing customer base through customer service and the product itself, and to potential customers through corporate communication via various media and SNS, directly resulting in a proactive ACT.

These factors increased the sales by more than $30 \%$ and maintained that level over two years.

As the next challenge, it is important to create a momentum that encourages customers to shift from indirect participation to participation in ongoing activities under RELATE. We believe this is an essential factor in developing a solid customer base from Western-style sweets to cosmetics. Other unique points were the addition of technical innovation and creation of an independent worldview for these cosmetics.

\section{References}

[1] Bernd H.Schmitt; Experiential Marketing: How to Get Customers to Sense, Feel, Think, Act, Relate; Free Press, 1999

[2] Bernd H. Schmitt Customer Experience Management; A Revolutionary Approach to Connecting with Your Customers; Wiley, 2003

[3] Shin'ya Nagasawa, editor, Waseda University Business School, Nagasawa Research Laboratories (Taro Yamamoto, Masahiko Yoshida, Yusuke Irisawa, Tsunehiro Yamamoto, Shinji Enoki): Hitmaking With Experiential Marketing - Manufacturing that Rocks the Boat, Nikka Giren Publishing, 2005.

[4] Shin'ya Nagasawa, editor: Creation of Experience Value in Long-Established Businesses - Customer Approach Management, Doyukan, 2006.

[5] Shin'ya Nagasawa, editor: Producing Experience Value, Nikka Giren Publishing, 2007.

[6] Shin'ya Nagasawa, editor: Premium Brand Strategies for Location and Traditional Industries - Technical Management that Generates Experience Value, Doyukan, 2009.

[7] Shin'ya Nagasawa, Takao Someya: Traditions and Innovations in the Veteran Brand Toraya - Experience Value Creation and Technical Management, Koyoshobo, 2007.

[8] Ginza Honey Bee Project, ed. "Humans, Flowers, and Honeybees in Ginza”, ON-BOOK, Ltd., 2007.

[9] Tanaka, Atsuo, : "Ginza Honeybee Story": To Create -Delicious-Landscape”, JIJI Press Publication

[10] Tanaka,Atsuo, et al. "New Ginza Science" Sanko-sha, 2009.via SNS and other media mentioned earlier.

[11] Nonaka, Ikujiro, and Akira Katsumi. "The Practical Wisdom of Innovation.” Nikkei Business Publication, 2010. 